\title{
Noise in hospital rooms and sleep disturbance in hospitalized medical patients
}

\author{
Marn Joon Park ${ }^{1}$, Jee Hee $\mathrm{Yoo}^{2}$, Byung Wook $\mathrm{Cho}^{3}$, Ki Tae Kim${ }^{4}$, Woo-Chul Jeong 5 , \\ Mina $\mathrm{Ha}^{6}$ \\ ${ }^{1}$ Department of Otolaryngology, Asan Medical Center, Seoul; ${ }^{2}$ Department of Internal Medicine, Hallym University Medical \\ Center, Chuncheon; ${ }^{3}$ Department of Internal Medicine, Dankook University Hospital, Cheonan; ${ }^{4}$ Department of Cardiothoracic \\ Surgery, Dankook University Hospital, Cheonan; ${ }^{5}$ Chungnam Workers' Health Center, Cheonan; ${ }^{6}$ Department of Preventive \\ Medicine, Dankook University College of Medicine, Cheonan, Korea
}

Objectives Hospitalized patients are vulnerable to sleep disturbances because of environmental stresses including noise. While most previous studies on hospital noise and sleep have been performed for medical machines in intensive care units, there is a limited data for patients hospitalized in medical wardrooms. The purpose of present study was to measure noise level of medical wardrooms, identify patient-perceived sources of noise, and to examine the association between noise levels and sleep disturbances in hospitalized patients.

Methods Noise dosimeters were used to measure noise level in 29 inpatient wardrooms at a university hospital. Sleep pattern and disturbance were assessed in 103 hospitalized patients, using the Pittsburgh Sleep Quality Index (PSQI) and Leeds Sleep Evaluation Questionnaire.

Results The mean equivalent continuous noise level for 24 hours was 63.5 decibel A (dBA), which was far higher than $30 \mathrm{dBA}$ recommended by the World Health Organization for hospital wardrooms. Other patients sharing a room were perceived as the most common source of noise by the patients, which was usually preventable. Of the patients in the study, $86 \%$ had bad sleep as assessed by the PSQI. The sleep disturbance was significantly correlated with increasing noise levels in a dose response manner.

Conclusions Systemic organizational interventions are needed to keep wardrooms private and quiet to reduce sleep disturbance.

Keywords Hospital noise, Medical wardrooms, Perceived noise, Quality assurance, Sleep disturbance

\author{
Correspondence: \\ Mina Ha, MD. PhD \\ 119 Dandae-ro, Dongnam-gu, \\ Cheonan 330-714, Korea \\ Tel: $+82-41-550-3854$ \\ Fax: +82-41-556-6461 \\ E-mail:minahaoo@gmail.com
}

Received: May 31, 2014

Accepted: July 25, 2014

Published online: August 18, 2014

This article is available from: http://e-eht.org/

\section{Introduction}

Sleep is a physiologic phenomenon that is essential for maintaining health, relieving stress and anxiety, and helping the body recover. Sleep can be disturbed by sudden environmental changes [1]. Sleep disturbance in hospitalized patients has been studied, and minimizing disruption of sleep cycle is currently considered as a part of patient care. Patients have been reported to experience improved or worsened neurological and cardio- vascular problems depending on the environmental stress from being hospitalized [2]. Sleep quality of hospitalized patients has been suggested to be considered as a part of routine medical evaluation, similar to routine vital signs checks [3].

Noise in hospital rooms was reported to be the most significant factor interfering with patient sleep [4-6]. Furthermore, higher ambient noise levels in hospitals were found to correlate with longer hospitalizations [7].

While most studies on hospital noise in association with sleep 
disturbance has focused on machine noises in intensive care units $[8,9]$, such investigations have been limited for patients in general hospital wardroom [2]. The purpose of this study was to measure the noise level of general medical hospital rooms for 24 hours, identify noise sources, assess sleep quality of inpatients, and examine the association between noise levels and sleep disturbance in these patients.

\section{Materials and Methods}

\section{Study Subjects}

The study enrolled patients who were hospitalized at an internal medicine department at a university hospital. A total of 103 patients in 29 wardrooms participated in the study. Patients were excluded from the study if they had been hospitalized less than three days to exclude possible effects of acute environmental changes and physical discomfort on patients' sleep disturbance, or if they had hearing problems, dementia, coma, severe psychiatric disorder, and communication problems. Data was collected for patient age and gender, number of roommates, duration of hospitalization, and patient-perceived sources of noise, by administering a questionnaire to participating patients. All analyses were performed after excluding any personal identifiers. This study was reviewed and approved by the institutional review board at the Dankook University Hospital. Written informed consent was obtained from all participants.

\section{Measuring the Noise Level of Rooms in the Hospital}

A total of 29 rooms were measured for ambient noise level using 13 dosimeters (Spark ${ }^{\circledR} 703$; Larson Davis 703 series, PCB Group Co., Provo, UT, USA) according to the guidelines from the Ministry of Environment, Korea [10]; the noise-meters were placed at ear level of patients, and were left to measure noise levels for 24 hours. Two noise level metrics, the equivalent continuous noise level $\left(\mathrm{L}_{\mathrm{eq}}\right)$ and the maximum noise level $\left(\mathrm{L}_{\max }\right)$, were used for all analyses.

\section{Sleep Disturbance Assessment}

In order to assess sleep quality of participating patients, the Korean version of Pittsburgh Sleep Quality Index (PSQI) and the Leeds Sleep Evaluation Questionnaire (LSEQ) were used. The PSQI is a self-administered questionnaire with 19 questions about overall sleep pattern, and is scored from 0 to 21 points [11] with higher scores indicating worse quality of sleep. The cut-off PSQI score of 5 was used to define sleep disturbance in this study. PSQI was originally designed to evaluate a person's sleep for the month leading up to the survey. Since patients in this study were admitted for less than a month (average of 13 days), we modified the PSQI questionnaire to assess "sleep quality during the hospitalization", rather than during the past one month.

The LSEQ was used to compare sleep patterns before and after hospitalization; it has 10 questions on sleep latency, quality of sleep, awakening from sleep, and behavior following wakefulness. Each question is scored from 0 to 10 [12], with higher scores reflecting improved sleep quality.

\section{Confounding Factors}

The severity of a patient's disease (levels 1,2, and 3 in order of severity) was evaluated according to the guidelines for hospital evaluation program 2006 [13], which consisted of 12 items, i.e., hygiene, self-urination/defecation, and nutritional status of patients. According to the university hospital drug formulary of 2009 [14], a list of sleep interfering drugs was generated as well as those that cause drowsiness and/or insomnia. Subsequently, the medical records of each patient were evaluated for these medications.

\section{Statistical Analysis}

The difference of noise levels among different types of rooms and difference in sleep disturbance according to the general characteristics of the patients were tested using $t$-test or analysis of variance. Multiple linear regression analyses were performed to examine the relationship between noise level and sleep disturbance, after adjusting for age, gender, severity of disease, medication of sleep interfering drug, and type of room. Estimation of lower limit of noise level required for no sleep disturbance was calculated by a simple regression model. All analyses were performed using SPSS version 14.0 (SPSS Inc., Chicago, IL, USA) with a two tailed significance level of 0.05 .

\section{Results}

\section{General Characteristics of Patients}

Males accounted for $59(57.2 \%)$ of the patients. The average age of the participating patients was 60 years of age, and $85 \%$ were between 40 and 70 . Two patients used a ward room without other patients ( 1 bed); one patient shared a room with another patient ( 2 beds); 37 shared room with three other patients (12 rooms with 4 beds each); and, 63 patients shared room with 5 other patients ( 14 rooms with 6 beds each). The most com- 
mon disease severity was level 2 (76.7\%). More than half of patients $(66 \%)$ took sleep-interfering drugs (Table 1$)$.

\section{Noise Level of the Hospital Rooms}

The median $\mathrm{L}_{\mathrm{eq}}$ noise was 64.2 and 60.9 decibel $\mathrm{A}$ (dBA) during the day and night, respectively, and 61.2 and $67.3 \mathrm{dBA}$ in 4-bed and 6-bed rooms, respectively. The median $\mathrm{L}_{\max }$ was also higher during day (86.1 dBA) than during night (80.4 dBA), but higher in 4-bedrooms (87.4 dBA) than in 6-bedrooms ( 85.3 $\mathrm{dBA})$. The differences between noise level during day and night

Table 1. Characteristics of study patients hospitalized in internal medicine department

\begin{tabular}{|c|c|c|}
\hline Variables & & $\begin{array}{l}\text { No. of patients } \\
(n=103)\end{array}$ \\
\hline Age, mean (SD) & $60.0(14.8)$ & \\
\hline \multirow{2}{*}{ Gender } & Male & 59 (57.2) \\
\hline & Female & $44(42.8)$ \\
\hline \multirow[t]{3}{*}{ Severity of disease ${ }^{a}$} & 1 (least severe) & $18(17.5)$ \\
\hline & 2 & $79(76.7)$ \\
\hline & 3 (most severe) & $6(5.8)$ \\
\hline \multirow[t]{2}{*}{ Medication of sleep interfering drug ${ }^{b}$} & No & $35(34.0)$ \\
\hline & Yes & $68(66.0)$ \\
\hline \multirow[t]{4}{*}{ Type of hospital rooms (bed) } & $1(n=2)$ & $2(1.9)$ \\
\hline & $2(n=1)$ & $1(1.0)$ \\
\hline & $4(n=12)$ & 37 (35.9) \\
\hline & $6(n=14)$ & $63(61.2)$ \\
\hline
\end{tabular}

Values are presented as number (\%).

aFrom Ministry of Health and Welfare. Guidelines for hospital evaluation program 2006 [13].

bFrom Dankook University Hospital. 2009 drug formulary [14]. was statistically significant while that between 4-beds and 6-bed rooms was not (Table 2).

\section{Sleep Disturbance of the Patients}

When compared to before hospitalization, getting to sleep, quality of sleep, awakening from sleep, and behavior following wakefulness were respectively worse in 44 (42.7\%), 57 (55.3\%), $46(44.7 \%)$, and 52 (50.5\%) of patients, as assessed by the LSEQ. Of the 103 patients, 89 (86\%) had disturbed sleep based on the PSQI score ( 5 or more). The PSQI scores were higher in female patients than in male $(p=0.06)$ patients, and was higher in patients with higher disease severity than those with lower disease severity $(p=0.04)$. The LSEQ-measure of sleep quality was better for patients who did not take sleep-interfering medicine than for those that did $(p=0.08)$ (Table 3$)$. Patient age and room type did not affect sleep disturbance patterns from the PSQI and LSEQ evaluations.

\section{Association between Noise Level and Sleep Disturbance in Patients}

Sleep disturbance scores significantly increased according to increases in the mean of the equivalent noise level in day and night even after adjustment for several potential confounders (age, gender, severity of patients' disease, medication of sleep interfering drug and type of room $)(\beta=0.20 ; 95 \%$ confidence interval $[\mathrm{CI}]=0.09-0.53$ for day, $\beta=0.12$; $95 \% \mathrm{CI}=0.07-0.36$ for night $)$. The maximum noise level, however, was not associated with

Table 2. Noise level of hospital rooms in internal medicine department according to time windows (unit; dBA)

\begin{tabular}{|c|c|c|c|c|c|c|c|}
\hline & \multirow{2}{*}{ All $(n=29)$} & \multirow{2}{*}{$p$-value ${ }^{\mathrm{a}}$} & \multicolumn{4}{|c|}{ Type of hospital rooms } & \multirow{2}{*}{$p$-value } \\
\hline & & & For 1 bed $(n=2)$ & For 2 beds $(n=1)$ & For 4 beds $(n=12)$ & For 6 beds $(n=14)$ & \\
\hline \multicolumn{8}{|l|}{24 Hours } \\
\hline $\begin{array}{l}\text { Leq }_{\text {eq }} \text { mean (Med) } \\
\text { (Min, Max) }\end{array}$ & $\begin{array}{l}63.6(64.4) \\
(55.7,70.7)\end{array}$ & $<0.05$ & $\begin{array}{l}64.5(64.5) \\
(60.3,68.7)\end{array}$ & $\begin{array}{l}70.7 \\
-\end{array}$ & $\begin{array}{l}62.7(61.2) \\
(55.7,68.3)\end{array}$ & $\begin{array}{l}63.8(67.3) \\
(57.0,69.1)\end{array}$ & 0.23 \\
\hline $\begin{array}{l}\mathrm{L}_{\max } \text { mean }(\mathrm{Med}) \\
(\operatorname{Min}, \mathrm{Max})\end{array}$ & $\begin{array}{l}86.6(86.5) \\
(79,7,99.9)\end{array}$ & $<0.05$ & $\begin{array}{l}84.2(84.2) \\
(79.7,88.7)\end{array}$ & 84 & $\begin{array}{l}86.8(87.4) \\
(80.0,93.6)\end{array}$ & $\begin{array}{l}86.6(85.3) \\
(80.0,99.9)\end{array}$ & 0.80 \\
\hline \multicolumn{8}{|c|}{ Day (07 am - 07 pm) } \\
\hline $\begin{array}{l}\text { Leq mean (Med) } \\
(\text { Min, Max) }\end{array}$ & $\begin{array}{l}64.4(64.2) \\
(57.9,70.7)\end{array}$ & & $\begin{array}{l}64.3(64.7) \\
(60.2,68.4)\end{array}$ & $\begin{array}{l}70.7 \\
-\end{array}$ & $\begin{array}{l}63.4(60.9) \\
(57.9,68.2)\end{array}$ & $\begin{array}{l}64.8(67.8) \\
(58.1,69.4)\end{array}$ & 0.07 \\
\hline $\begin{array}{l}L_{\max } \text { mean }(M e d) \\
(\text { Min, Max })\end{array}$ & $\begin{array}{l}86.1(86.1) \\
(79.7,99.9)\end{array}$ & & $\begin{array}{l}84.2(78.8) \\
(79.7,88.7)\end{array}$ & 84 & $\begin{array}{l}86.3(83.0) \\
(80.0,93.6)\end{array}$ & $\begin{array}{l}86.1(80.4) \\
(80.0 .99 .9)\end{array}$ & 0.80 \\
\hline \multicolumn{8}{|c|}{ Night (07 pm - 07 am) } \\
\hline $\begin{array}{l}\text { Leq }_{\text {mean }}(\mathrm{Med}) \\
(\text { Min, Max) }\end{array}$ & $\begin{array}{l}62.2(60.9) \\
(50.9,70.7)\end{array}$ & & $\begin{array}{l}64.7(64.3) \\
(60.4,68.9)\end{array}$ & $\begin{array}{c}70.7 \\
-\end{array}$ & $\begin{array}{l}61.2(63.2) \\
(50.9,68.6)\end{array}$ & $\begin{array}{l}62.6(66.9) \\
(53.6,69.3)\end{array}$ & 0.27 \\
\hline $\begin{array}{l}\mathrm{L}_{\max } \text { mean }(\mathrm{Med}) \\
(\operatorname{Min}, \mathrm{Max})\end{array}$ & $\begin{array}{l}81.5(80.4) \\
(71.0,98.6)\end{array}$ & & $\begin{array}{l}78.6(84.2) \\
(77.9,79.6)\end{array}$ & 76.9 & $\begin{array}{l}81.4(86.9) \\
(71.0,87.4)\end{array}$ & $\begin{array}{l}81.7(86.1) \\
(73.5,98.6)\end{array}$ & 0.84 \\
\hline
\end{tabular}

All $p$-values were calculated by comparing mean noise level using $t$-test.

$L_{e q}$, Equivalent continuous level of noise; $L_{\max }$ Maximum level of noise; Min, minimum; Med, median; Max, maximum.

aBetween day and night time in all rooms.

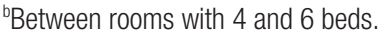


Table 3. Sleep disturbance pattern according to hospitalized patients' characteristics in internal medicine department

\begin{tabular}{|c|c|c|c|c|c|c|c|}
\hline & & & & & leep disturba & & \\
\hline & & $n$ & & & & & \\
\hline & & & PSQI & $\begin{array}{l}\text { Getting } \\
\text { to sleep }\end{array}$ & $\begin{array}{l}\text { Quality } \\
\text { of sleep }\end{array}$ & $\begin{array}{l}\text { Awakening } \\
\text { of sleep }\end{array}$ & $\begin{array}{l}\text { Behavior of following } \\
\text { wakefulness }\end{array}$ \\
\hline Gender & Male & 59 & $8.03(3.52)$ & $4.45(1.64)$ & $4.18(1.53)$ & $4.44(1.50)$ & $4.29(1.52)$ \\
\hline & Female & 44 & $9.34(3.42)$ & $4.93(1.56)$ & $3.84(1.71)$ & $4.33(1.44)$ & $3.96(1.67)$ \\
\hline & $p$-value & & 0.06 & 0.91 & 0.52 & 0.99 & 0.30 \\
\hline Age (yr) & $17-53$ & 35 & $8.49(3.43)$ & $4.19(1.74)$ & $3.82(1.69)$ & $4.33(1.56)$ & $3.76(1.67)$ \\
\hline & $54-70$ & 34 & $9.00(3.65)$ & $4.54(1.66)$ & $3.71(1.71)$ & $4.23(1.49)$ & $4.11(1.56)$ \\
\hline & $71-82$ & 34 & $8.29(3.56)$ & $5.29(1.36)$ & $4.64(1.39)$ & $4.64(1.37)$ & $4.63(1.49)$ \\
\hline & $p$-value & & 0.70 & 0.27 & 0.18 & 0.69 & 0.27 \\
\hline Severity of patients' & Less severe & 18 & $7.22(2.86)$ & $5.08(1.88)$ & $3.80(1.99)$ & $5.32(1.34)$ & $4.99(1.58)$ \\
\hline disease $^{\mathrm{a}}$ & More severe & 85 & $8.88(3.60)$ & $4.56(1.55)$ & $4.08(1.53)$ & $4.22(1.48)$ & $3.98(1.57)$ \\
\hline & $p$-value & & 0.04 & 0.17 & 0.14 & 0.62 & 0.30 \\
\hline Medication of sleep & Yes & 68 & $8.62(3.75)$ & $4.35(1.65)$ & $3.85(1.60)$ & $4.39(1.43)$ & 3.89 (1.59) \\
\hline interfering drug & No & 35 & $8.54(3.08)$ & $5.29(1.47)$ & $4.41(1.63)$ & $4.40(1.56)$ & $4.69(1.53)$ \\
\hline & $p$-value & & 0.92 & 0.57 & 0.08 & 0.15 & 0.57 \\
\hline Type of rooms (bed) & 1 & 2 & $7.50(3.54)$ & $4.58(1.82)$ & 4.95 (1.63) & $4.81(1.16)$ & $3.00(1.77)$ \\
\hline & 2 & 1 & 8.00 & 6.00 & 3.00 & 7.00 & 7.00 \\
\hline & 4 & 37 & $8.65(3.15)$ & $4.80(1.59)$ & $4.09(1.77)$ & $4.61(1.36)$ & $4.61(1.50)$ \\
\hline & 6 & 63 & $8.60(3.80)$ & 4.55 (1.63) & 4.03 (1.52) & $4.39(1.54)$ & 4.14 (1.61) \\
\hline & $p$-value ${ }^{\mathrm{b}}$ & & 0.97 & 0.91 & 0.62 & 0.41 & 0.18 \\
\hline
\end{tabular}

Values are presented as mean (standard deviation).

Sleep disturbance assessed by Pittsburgh Sleep Quality Index (PSQI) and Leeds Sleep Evaluation Questionnaire (LSEQ).

All $p$-values were calculated using $t$-test or ANOVA.

'Severity of patients' disease: less severe (score 1 or 2), more severe (score 3).

${ }^{b}$ Comparison of sleep disturbance scores in patients in room for 4 beds with those in room for 6 beds.

Table 4. Association between noise level of room in internal medicine department and sleep disturbance of hospitalized patients

\begin{tabular}{|c|c|c|c|c|c|c|}
\hline \multirow{3}{*}{ Noise in rooms } & \multicolumn{6}{|c|}{ PSQI score } \\
\hline & \multicolumn{3}{|c|}{ Unadjusted } & \multicolumn{3}{|c|}{ Adjusted $^{\mathrm{a}}$} \\
\hline & $\beta$ & SE & $95 \% \mathrm{Cl}$ & $\beta$ & SE & $95 \% \mathrm{Cl}$ \\
\hline \multicolumn{7}{|c|}{ Equivalent noise level (dBA) } \\
\hline 24 Hours & 0.22 & 0.08 & $0.07,0.37^{*}$ & 0.20 & 0.07 & $0.05,0.42^{*}$ \\
\hline Day & 0.24 & 0.09 & $0.06,0.42^{*}$ & 0.20 & 0.09 & $0.09,0.53^{*}$ \\
\hline Night & 0.13 & 0.06 & $0.01,0.24^{*}$ & 0.12 & 0.06 & $0.07,0.36^{\star}$ \\
\hline \multicolumn{7}{|c|}{ Maximum noise level (dBA) } \\
\hline 24 Hours & 0.16 & 0.07 & $0.02,0.30^{*}$ & 0.13 & 0.07 & $0.01,0.32^{*}$ \\
\hline Day & 0.13 & 0.08 & $-0.02,0.23$ & 0.10 & 0.07 & $-0.01,0.48$ \\
\hline Night & 0.11 & 0.06 & $-0.01,0.24$ & 0.12 & 0.06 & $-0.01,0.21$ \\
\hline
\end{tabular}

Sleep disturbance assessed by the Pittsburgh Sleep Quality Index (PSQl).

$\mathrm{SE}$, standard error; $\mathrm{Cl}$, confidence interval.

aParameter estimated using multiple linear regression model adjusted for age, gender, severity of patients' disease, medication of sleep interfering drug, and type of room.

${ }^{\star} p<0.05$.

sleep disturbance during day or night (Table 4). Sleep disturbance measured by the LSEQ did not show a significant association with ambient noise level of hospital rooms (data not shown).

\section{The Noise Level Required for No Sleep Disturbance in Hospitalized Patients}

The estimated limits of $L_{e q}\left(L_{\max }\right)$ required for no sleep distur- bance (PSQI score less than 5) were calculated to be 49.3 (59.3 $\mathrm{dBA})$ at daytime, $34.2(50.5 \mathrm{dBA})$ at night time, on linear regression model.

\section{Perceived Sources of Noise}

The most common sleep disturbed patient-perceived sources of noise was noise caused by other patients' caregivers and visi- 
Table 5. Perceived sources of noise by hospitalized patients in internal medicine department

\begin{tabular}{lccc}
\hline Perceived sources of noise $^{\mathrm{a}}$ & All & Patients not disturbed sleep $^{\mathrm{b}}(\mathrm{n}=14)$ & Patients disturbed sleep $^{\mathrm{b}}(\mathrm{n}=89)$ \\
\hline Other patients' caregivers or visitors & $22(21.4)$ & $1(7.1)$ & $21(23.6)$ \\
Other patients' snoring & $18(17.5)$ & $0(0.0)$ & $18(20.2)$ \\
Toilet flushing & $16(15.5)$ & $3(21.4)$ & $13(14.6)$ \\
Cartwheel sound & $14(13.6)$ & $1(7.1)$ & $13(14.6)$ \\
Telephone and TV & $13(12.6)$ & $0(0.0)$ & $13(14.6)$ \\
Personal medical device & $11(10.7)$ & $2(14.3)$ & $9(10.1)$ \\
Procedure by medical staffs & $10(9.7)$ & $0(0.0)$ & $10(11.2)$
\end{tabular}

Values are presented as number (\%).

apatients could respond to multiple sources.

bSleep disturbance assessed by the Pittsburgh Sleep Quality Index.

tors (23.6\%), followed by noise caused by other patients such as snoring or groaning, toilet flushing, medication/food carts and phone or TV sound, personal medical staff, and medical devices (Table 5).

\section{Discussion}

The results of this study indicated that the equivalent (maximum) noise level of wardrooms in the university hospital to be 63.6 dBA (86.6 dBA), which was higher than the recommended level by the domestic policies in South Korea [10] as well as by the World Health Organization (WHO) [15]. Among various sources, noise from other patients or caregivers sharing the rooms was the most common type of disturbance. Of the study participants, $86 \%$ experienced sleep disturbance that was significantly associated with noise levels in hospital rooms, after adjusting for several confounding factors.

An interesting finding was that patient-perceived sources of noise in medical wardrooms were different from those reported for intensive care units (noises of human activity versus machines). Although there were no statistically significant differences in noise level between types of room, the $\mathrm{L}_{\max }$ at night was lower in 1- or 2-bed rooms than for 4- or 6-bed rooms. In addition, PSQI scores were higher among patients in 4- or 6-bed rooms than those in 1- or 2-bed rooms. Along with these findings, "human" sources of noise (caregivers, visitors or snoring roommates) were reported by the sleep disturbed patients as the main sources of noise in medical wardrooms rather than structural sources in hospital buildings. These types of noise sources are usually preventable [16] by an appropriate hospital environmental management. Furthermore, even in the medical wardroom, noise was associated with sleep disturbances, which suggests that a different interventional approach is necessary to reduce sleep disturbance in medical wardrooms.

In terms of sleep disturbance, noise levels have been reported from 50 to $75 \mathrm{dBA}$ with the highest night peak reaching 103 $\mathrm{dBA}$ in intensive care units [9] and $48 \mathrm{dBA}$ in $\mathrm{L}_{\text {eq }}$ and $80.3 \mathrm{dBA}$ in $\mathrm{L}_{\max }$ in medical inpatient rooms [16]. Noise levels measured in our study were similar (or a bit higher) with these previous findings. The WHO's recommended noise levels are $30 \mathrm{dBA}$ inside hospital wardrooms for sleep disturbance prevention [15], and $50 \mathrm{dBA}$ for day and $40 \mathrm{dBA}$ for night have been recommended by the Korea Ministry of Environment [10]. These recommended values are much lower than those noise levels measured in present study. In addition, the limits of noise level for no sleep disturbance were estimated to be $49.3 \mathrm{dBA}$ at day and $34.24 \mathrm{dBA}$ at night in the present study, which are similar to existing recommendations, indicating the validity of this study.

In South Korea, most hospitals have five to six patients in one room, and therefore are less quiet and associated with more discomfort with regards to sleeping [17]. About $80 \%$ of hospitalized patients reported that they were frequently woken up during sleep and did not feel that they were refreshed after sleep. More than half complained that the total amount of sleep decreased after hospitalization in a medical department [18]. Moreover, older patients were prescribed more neuroleptic drugs, which suggests that they need more advanced care with regard to sleeping [19].

Noise was reported to be the most common factor interfering with sleep among inpatients $[2,4,5]$. Higher levels of noise are associated with increased use of anesthetic drugs [20], which can lengthen the duration of hospitalization [7]. Noise increases production of angiotensin II in the blood and can increase the risk of a stroke [21], increases cholesterol and triglyceride levels and the risk of diabetes [22], triggers elevation of blood pressure and pulse rate, and increases muscle tension, intracranial pressure, skin electrical resistance, sweating, contraction of peripheral blood vessels and hearing impairment [23]. Therefore, noise control is important for patient satisfaction and health outcomes in the hospital setting.

The present study has some limitations. The small sample size limits statistical power of the analyses. The finding that sleep disturbance measured by the LSEQ did not show a significant association with ambient noise level of hospital rooms in the 
present study might be due to lack of statistical power, or the different sensitivity and validity compared to the PSQI in measurement of sleep disturbance. Second, because of the limited functions of noise dosimeters, we could not analyze the detailed noise characteristics, i.e., duration, impulsiveness, and tonal quality and etc., in relation with the sleep quality, which might provide some insights on the biophysical mechanism of noiseinduced sleep. Third, patients' mood state, i.e., stress, anxiety and depression, affects sleep quality and may play as a confounding factor in association between noise and sleep disturbance in medical patients. However, such information was not available in the present study.

The noise level in internal medicine ward rooms at a university hospital was demonstrated to be higher than recommended levels. Increasing levels of noise were associated with higher rates of sleep disturbance in hospitalized patients. The main sources of patient-perceived noise were other patients sharing the same room. The hospital management on human sources of noise (restricting visiting time and duration and decreasing number of beds in a room) are needed.

\section{Conflict of Interest}

The authors have no conflicts of interest with material presented in this paper.

\section{References}

1. Kim SM. Sleep pattern and related factors of healthy adults. J Korean Acad Psychiatr Ment Health Nurs 1997; 6(1):116-131 (Korean).

2. Tembo AC, Parker V. Factors that impact on sleep in intensive care patients. Intensive Crit Care Nurs 2009;25(6):314-322.

3. Young JS, Bourgeois JA, Hilty DM, Hardin KA. Sleep in hospitalized medical patients, part 1: factors affecting sleep. J Hosp Med 2008;3(6):473-482.

4. Kim MY, Cho SH, Lee SM, Jung SJ, Park KS. Elderly sleep pattern and disturbing factors before and after hospitalization. J Korean Acad Nurs 1999;29(1):61-71 (Korean).

5. Lei Z, Qiongjing Y, Qiuli W, Sabrina K, Xiaojing L, Changli W. Sleep quality and sleep disturbing factors of inpatients in a Chinese general hospital. J Clin Nurs 2009; 18(17):2521-2529.

6. Park HS, Kim KH. Perceived noise in patients and discomfort due to noise. J Korean Acad Soc Nurs Educ 1997;3(2):150-162 (Korean).
7. Grumet GW. Pandemonium in the modern hospital. N Engl J Med 1993;328(6):433-437.

8. Patel M, Chipman J, Carlin BW, Shade D. Sleep in the intensive care unit setting. Crit Care Nurs Q2008;31(4):309-318.

9. Xie H, Kang J, Mills GH. Clinical review: The impact of noise on patients' sleep and the effectiveness of noise reduction strategies in intensive care units. Crit Care 2009;13(2):208.

10. Ministry of Environment. Regulation on noise and vibration, reinforcement regulations. Article 20, 3, regulation level on noise and vibration in daily life; 2010 [cited 2014 Jul 26]. Availble from: http://www.law.go.kr/lsSc.do?menuId=0\&p1=\&subMenu=1\&n wYn $=1 \&$ query $=\% \mathrm{EC} \% 86 \% 8 \mathrm{C} \% \mathrm{EC} \% 9 \mathrm{D} \% 8 \mathrm{C} \& \mathrm{x}=0 \& \mathrm{xy}=0 \# \mathrm{AJAX}$ (Korean).

11. Buysse DJ, Reynolds CF 3rd, Monk TH, Berman SR, Kupfer DJ. The Pittsburgh Sleep Quality Index: a new instrument for psychiatric practice and research. Psychiatry Res 1989;28(2):193-213.

12. Zisapel N, Nir T. Determination of the minimal clinically significant difference on a patient visual analog sleep quality scale. J Sleep Res 2003;12(4):291-298.

13. Ministry of Health and Welfare. Guidelines for hospital evaluation program 2006 [cited 2014 Aug 12]. Available from: http://www. khidi.or.kr/etcsite/medicalnotice.do?mode $=$ view\&code $=1101 \&$ menuCd $=30140101 \&$ no $=186 \&$ type $=$ ALL \& cpage $=8 \&$ searchIte $\mathrm{m}=0$ \&searchKey= (Korean).

14. Dankook University Hospital. 2009 drug formulary. Version 9. Cheonan; Dankook University Hospital. 2009 (Korean).

15. World Health Organization. Guidelines for community noise; 1996 [cited 2014 Jul 26]. Available from: http://www.who.int/docstore/peh/noise/Commnoise4.htm.

16. Yoder JC, Staisiunas PG, Meltzer DO, Knutson KL, Arora VM. Noise and sleep among adult medical inpatients: far from a quiet night. Arch Intern Med 2012;172(1):68-70.

17. Southwell MT, Wistow G. Sleep in hospitals at night: are patients' needs being met? J Adv Nurs 1995;21(6):1101-1109.

18. Yinnon AM, Ilan Y, Tadmor B, Altarescu G, Hershko C. Quality of sleep in the medical department. Br J Clin Pract 1992;46(2):88-91.

19. Flaherty JH. Insomnia among hospitalized older persons. Clin Geriatr Med 2008;24(1):51-67.

20. Aitken RJ. Quantitative noise analysis in a modern hospital. Arch Environ Health 1982;37(6):361-364.

21. Dengerink HA, Wright JW, Thompson P, Dengerink JE. Changes in plasma angiotensin II with noise exposure and their relationship to TTS. J Acoust Soc Am 1982;72(1):276-278.

22. Lovallo WR, Pishkin V. A psychophysiological comparison of type $\mathrm{A}$ and $\mathrm{B}$ men exposed to failure and uncontrollable noise. Psychophysiology 1980;17(1):29-36.

23. Chung KC. Health hazards due to noise. J Korean Med Assoc 1971;14(12):13-16 (Korean). 